\title{
Avaliação dos conhecimentos dos utentes de uma USF do Grande Porto sobre o rastreio do cancro da próstata
}

Marta Magalhães, ${ }^{*}$ Joana Almeida, ${ }^{* *}$ José Eduardo Oliveira,*** Caroline Silva****

\section{RESUMO}

Objetivo: Avaliar o grau de conhecimento dos utentes da Unidade de Saúde Familiar Camélias face ao rastreio do cancro da próstata. Tipo de estudo: Estudo observacional transversal.

Local: USF Camélias.

População: Utentes da USF Camélias, do sexo masculino, entre os 40 e os 74 anos.

Métodos: Da população de 3.067 utentes foi selecionada uma amostra aleatória e estratificada de 500 indivíduos. $O$ conhecimento dos utentes sobre o rastreio do cancro da próstata foi avaliado através de um questionário, aplicado mediante entrevista telefónica.

Resultados: Dos 308 utentes que aceitaram participar no estudo, 77,9\% já tinham ouvido falar do teste prostate specific antigen (PSA) (47,7\% pelo seu médico de família). A maioria afirmou que os homens deveriam realizar o teste PSA pelo menos a cada dois anos a partir dos 40-50 anos; contudo, relativamente ao exame do toque retal, uma percentagem de $43,8 \%$ não respondeu ou afirmou não conhecer as recomendações.

Conclusão: Os utentes desta USF do Grande Porto estão moderadamente informados sobre os métodos de rastreio do cancro da próstata. São necessários mais estudos nesta área, preferencialmente multicêntricos, de forma a poder extrapolar os resultados para a população portuguesa.

Palavras-chave: PSA; Rastreio; Conhecimento.

\section{INTRODUÇÃO}

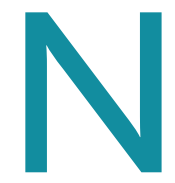

a Europa, o cancro da próstata afeta cerca de $12 \%$ de todos os homens ${ }^{1}$ e, em Portugal, é a segunda causa de morte por cancro, logo a seguir ao cancro do pulmão. ${ }^{2}$ Em 2012, 1.745 homens faleceram por tumor maligno da próstata. Os dados sobre incidência desta neoplasia remontam a 2009 e apontam para uma taxa bruta de 108,81/100.000 habitantes-ano. Da carga global de doença expressa em Years Lived with Disability (YLD), o tumor maligno da próstata ocupa o terceiro lugar com $0,21 \%$ do total de YLD por

* Mestre em Medicina. Médica Interna de 2. ${ }^{\circ}$ ano de Medicina Geral e Familiar da Unidade de Saúde Familiar Camélias

**Mestre em Medicina. Médica Interna de $3 .^{\circ}$ ano de Medicina Geral e Familiar da Unidade de Saúde Familiar Camélias

***Mestre em Medicina. Médico Interno de $4 .^{\circ}$ ano de Medicina Geral e Familiar da Unidade de Saúde Familiar Camélias

****Aluna de Mestrado em Matemática para Professores da Faculdade de Ciências da Universidade do Porto tumores malignos, sendo apenas ultrapassado pelo tumor maligno da mama feminina e do cólon e reto. ${ }^{3}$

O teste PSA e o exame do toque retal (TR) têm sido tradicionalmente usados como métodos de rastreio para o cancro da próstata, ${ }^{4}$ mas a sua utilização tem sido cada vez mais contestada por ausência de evidência de benefício.

A maioria das organizações médicas não recomenda o rastreio do cancro da próstata baseado no teste PSA e concorda que os doentes devem discutir os riscos e benefícios deste rastreio com o seu médico para que tomem uma decisão informada. ${ }^{5} \mathrm{O}$ médico deve abordar com o seu paciente aspetos como a incidência, mortalidade, número necessário de pessoas rastreadas para evitar uma morte por cancro da próstata, bem como os riscos inerentes a este rastreio.

A Direção-Geral da Saúde (DGS) recomenda, na Norma de Orientação Clínica (NOC) emitida em 2011 e atua- 
lizada em 2014, contra a utilização do PSA no rastreio populacional de cancro da próstata (nível de evidência B). Aconselha, no entanto, a prescrição anual deste exame, em homens entre os 40 e os 74 anos, acompanhada ou não da palpação prostática através do exame do TR aos homens que o solicitem, depois de devidamente informados (nível de evidência A). ${ }^{6}$

Vários organismos internacionais emitiram pareceres sobre este tema. Em 2013, a Cochrane publicou uma meta-análise de cinco ensaios clínicos aleatorizados sobre o rastreio do cancro da próstata e concluiu que este não diminui de forma significativa a mortalidade por esta neoplasia. Dos estudos incluídos nesta meta-análise apenas um descreveu benefícios do rastreio no sub-grupo dos homens entre os 55 e os 69 anos. Os autores da meta-análise da Cochrane concluem que os utentes devem ser informados de que, mesmo neste subgrupo, 1.410 homens têm que ser rastreados e 48 têm que ser diagnosticados com cancro da próstata para prevenir uma morte por esta causa ao fim de 10 anos. $^{7}$

A European Association of Urology $y^{8}$ sugere que o rastreio do cancro da próstata através do PSA sérico pode ser iniciado aos 40 anos. Posteriormente, se o PSA for $\leq 1 \mathrm{ng} / \mathrm{mL}$, o risco de desenvolver cancro prostático é baixo, pelo que uma nova medição poderá ser novamente solicitada após oito anos.

A American Urological Association ${ }^{9}$ recomenda que o teste PSA seja realizado em conjunto com exame do TR a partir dos 50 anos para os homens com risco médio. Para aqueles com risco mais elevado (história familiar de cancro da próstata em parente de $1 .^{\circ}$ grau e raça negra) deve ser realizado mais precocemente.

A American Cancer Society ${ }^{4}$ recomenda que a discussão sobre o rastreio com o médico deve ser iniciada aos 50 anos para os indivíduos com risco médio, aos 45 anos para aqueles com alto risco (história familiar de cancro da próstata em parente de $1 .^{\circ}$ grau e raça negra) e aos 40 anos para os que apresentam um risco ainda mais elevado (mais de um parente em $1 .{ }^{\circ}$ grau com cancro da próstata). Após a discussão, o rastreio deve ser realizado com o teste PSA, possivelmente, associado ao exame do TR. O rastreio deverá ser bienal para valores de PSA inferiores a $2,5 \mathrm{ng} / \mathrm{ml}$ e anual para valores iguais ou acima deste.

A Canadian Task Force on Preventive Health Care ${ }^{10}$ recomenda contra a utilização de PSA para rastreio de cancro da próstata em todas as faixas etárias, ainda que com graus de recomendação diferentes: idade menor que 55 anos e maior ou igual a 70 anos com recomendação forte e entre os 55 e os 69 anos com recomendação fraca, havendo lugar à decisão informada de cada homem.

A United States Preventive Services Task Force (USPSTF), em 2012, ${ }^{11}$ fez uma recomendação contra o rastreio do cancro da próstata, concluindo que existe certeza moderada-elevada de que o rastreio através do PSA não tem saldo benéfico ou que os riscos ultrapassam os benefícios (grau de recomendação D) e sugere a ecografia e o TR como outros métodos de deteção de cancro da próstata a serem considerados, além dos níveis séricos de PSA.

Nenhuma das sociedades científicas referidas acima (assim como a American Cancer Society, American Society of Clinical Oncology, American College of Family Physicians, American College of Preventive Medicine, entre outras) recomenda o rastreio sistemático e universal do cancro da próstata sem considerar as suposições e dúvidas que se têm colocado. ${ }^{12}$

A atitude clínica proativa não deve ser determinante do rastreio, mas a decisão informada do paciente. ${ }^{2,9,13}$

Segundo a pesquisa efetuada, foram encontrados dois estudos semelhantes a este, um australiano e outro canadiano ${ }^{14-15}$ e nenhum em Portugal.

O objetivo principal deste trabalho consistiu na avaliação do grau de conhecimento dos utentes da USF Camélias sobre rastreio do cancro da próstata para, desta forma, perceber se a prática médica está a ser correta neste âmbito.

\section{MÉTODOS}

Trata-se de um estudo observacional transversal com componente analítica, realizado na USF Camélias, em Vila Nova de Gaia.

A realização deste estudo foi aprovada pela Comissão de Ética da ARS Norte, após submissão do respetivo protocolo.

O cálculo da dimensão amostral teve por base a população dos utentes da USF Camélias do género masculino com idades entre os 40 e 74 anos $(n=3.067)$ e foi efetuado com recurso ao programa informático Epi Info $^{\mathrm{TM}}$ 7, utilizando a função STATCALC. A dimensão da amostra, para uma prevalência esperada de $50 \%$, com um nível de precisão de $5 \%$ e um nível de confiança de $95 \%$, foi de 342, tendo sido planeado um incremento amostral de aproximadamente $45 \%$, de forma a prevenir eventuais 
perdas de poder estatístico por recusa de participação, obtendo-se uma amostra final de 500 utentes. De forma a manter a homogeneidade dos grupos, realizou-se a estratificação da amostra consoante o grupo etário. Estratificou-se a amostra em sete subgrupos proporcionais à população $(40$ - 44, 45 - 49, 50 - 54, 55 - 59, 60 - 64, 65 69, 70 - 74 anos). Portanto, dos 500 utentes na amostra 73 tinham 40 - 44 anos, 80 tinham $45-49$ anos, 87 tinham 50 - 54 anos, 78 tinham $55-59$ anos, 72 tinham $60-64$ anos, 63 tinham 65 - 69 anos e 47 tinham $70-74$ anos.

Foram excluídos os utentes que recusaram participar no estudo, sem compreensão e expressão oral de língua portuguesa ou com história de cancro da próstata.

Os dados foram colhidos em outubro e novembro de 2013 através um questionário (em anexo), elaborado pelos investigadores com base na literatura, ${ }^{14-15}$ para possibilitar a comparação de resultados. Este questionário foi submetido a teste-piloto, obedecendo aos mesmos procedimentos descritos na operacionalização da recolha de dados. Foram preenchidos 10 testes-piloto, tendo-se concluído pela ausência de necessidade de efetuar alterações ao questionário inicial.

O preenchimento dos questionários foi feito através de entrevista telefónica. Os consentimentos informados foram obtidos oralmente previamente à realização dos inquéritos. Foi realizado um contacto telefónico prévio por um administrativo da USF para obtenção do consentimento. Posteriormente, os investigadores realizaram três tentativas de chamadas telefónicas.

O referido questionário contemplou 15 questões de escolha múltipla, que englobavam: 1) características sóciodemográficas; 2) avaliação do conhecimento sobre rastreio do cancro da próstata. Durante a aplicação do questionário ao doente foi explicado o significado de teste PSA ("é uma análise ao sangue para identificar problemas da próstata") e de exame do TR ("é um exame em que o médico introduz um dedo no ânus para palpar a próstata").

Como variáveis independentes foram consideradas: idade e escolaridade do utente e história familiar de cancro da próstata. As variáveis dependentes consideradas foram conhecimento sobre PSA e TR e abordagem das vantagens e desvantagens destes exames pelo médico de família (MF).

O tratamento estatístico dos dados foi efetuado usando o software Statistical Package for the Social Sciences (SPSS) $20.0 \AA$, recorrendo a técnicas de estatística des- critiva e inferencial. As variáveis categóricas são apresentadas como contagem (percentagem) e as variáveis contínuas como média (desvio-padrão). Foram utilizados diversos testes, consoante as variáveis estudadas. Os testes Qui-Quadrado, McNemar e Binominal foram usados para verificar a presença de associações entre variáveis categóricas. Os testes Kruskal-Wallis, Wilcoxon Signed Ranks e Mann-Whitney foram usados para comparar distribuições de variáveis quantitativas ordinais com outras variáveis. O nível de significância adotado foi 0,05 e os intervalos de confiança de $95 \%$.

\section{RESULTADOS}

Dos 500 utentes, $26(5,2 \%)$ recusaram responder e 162 $(32,4 \%)$ não atenderam o telefone após três tentativas. No total, 312 utentes completaram o questionário, via telefone; no entanto, quatro foram excluídos por terem história pessoal de cancro da próstata (figura 1).

As características sóciodemográficas dos 308 participantes encontram-se no quadro I. A média de idades dos utentes foi de 57,66 anos, verificando-se uma predominância do intervalo de idades de 60 - 64 anos. A maioria (99\%) era de raça caucasiana, cerca de 38,3\% tinham o $1^{\circ}$ ciclo de escolaridade e $16,9 \%$ dos utentes tinham formação superior (o único utente que escolheu a opção "Outro" detinha um grau de mestrado).

Dos 308 utentes, 5,5\% tinham história familiar de cancro da próstata.

Desta amostra, 77,9\% afirmaram já ter ouvido falar do PSA, 47,7\% através do MF e cerca de metade (52,3\%) já tinham realizado o teste PSA. Grande parte $(61,7 \%)$ declarou que o MF discutiu as vantagens de realizar este exame, ao passo que apenas $20,1 \%$ afirmaram o mesmo sobre as desvantagens do exame.

Relativamente ao exame do TR, 47,7\% afirmaram já ter ouvido falar sobre este exame, 26,6\% através do MF e $35,1 \%$ já tinham efetuado um TR.

No quadro II estão os resultados das perguntas que avaliaram o conhecimento específico dos utentes sobre o rastreio do cancro da próstata.

Como se evidencia, a maioria dos utentes $(50,6 \%$ e $71,8 \%$, respetivamente) respondeu que o teste PSA deve ser realizado pelo menos a cada dois anos e a partir dos 40 - 50 anos. Relativamente ao TR, a maioria $(62,3 \%$ e $43,8 \%$, respetivamente) escolheu a hipótese $40-50$ anos para a idade inicial e a hipótese "Não Sei/Não 


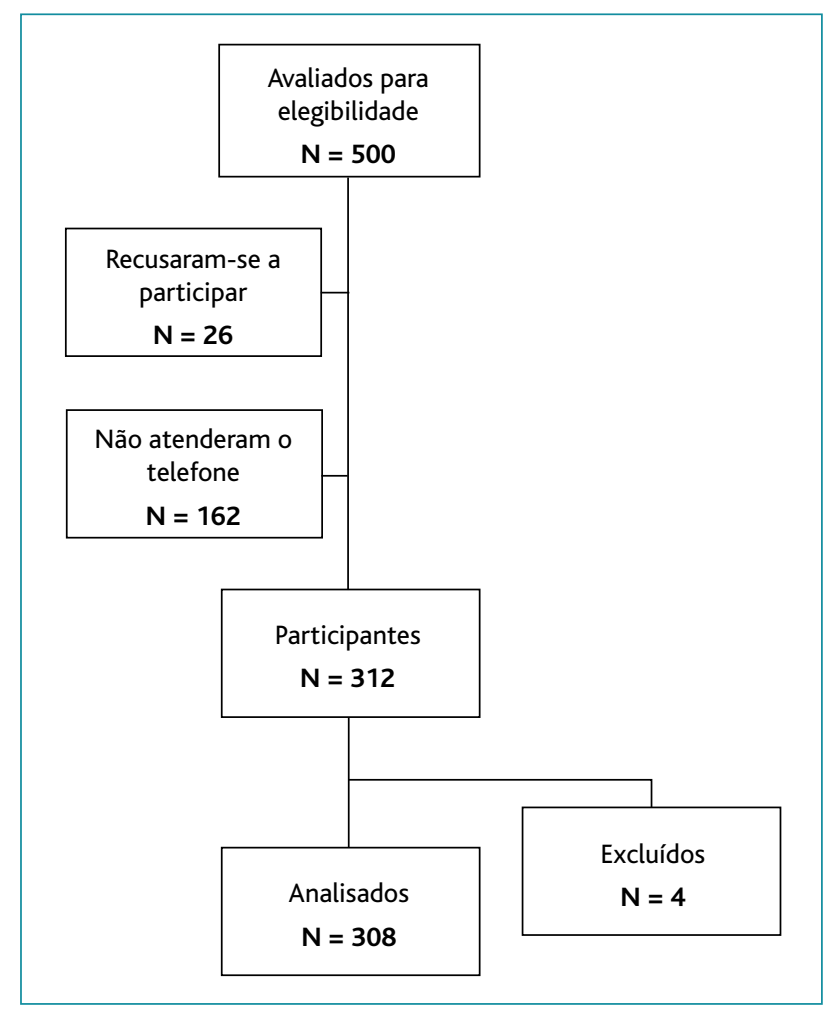

Figura 1. Fluxograma dos utentes do estudo.

Respondo" para a periodicidade; contudo, se esta última parcela não for contabilizada, as respostas relativas à periodicidade do TR dividiram-se entre realizar o exame a cada dois anos (19,8\%), realizar o exame só quando o utente refere sintomatologia $(17,5 \%)$ ou realizar o exame a cada 3 anos (14\%).

Neste estudo verificou-se que, à medida que aumenta a idade, maior é a probabilidade de o utente já ter ouvido falar do teste PSA $(p=0,039)$ e do exame do TR $(p<0,001)$ e maior é a probabilidade de ter sido o MF a ter falado sobre estes exames complementares de diagnóstico $(p<$ 0,001 e $p=0,027$, respetivamente). Além disso, evidenciou-se ainda que a idade dos utentes não estava relacionada com a discussão das vantagens nem das desvantagens pelo MF ( $p=0,090$ e $p=0,373$, respetivamente).

Verificou-se que ouvir falar sobre o teste PSA $(n=240)$ e sobre o exame do TR $(n=145)$ não é independente da escolaridade ( $p=0,003$ e $p=0,01)$. Contudo, não houve uma relação estatisticamente significativa entre o nível da escolaridade e ser o MF a falar aos utentes sobre o PSA ou TR ou a discussão das vantagens e das desvantagens

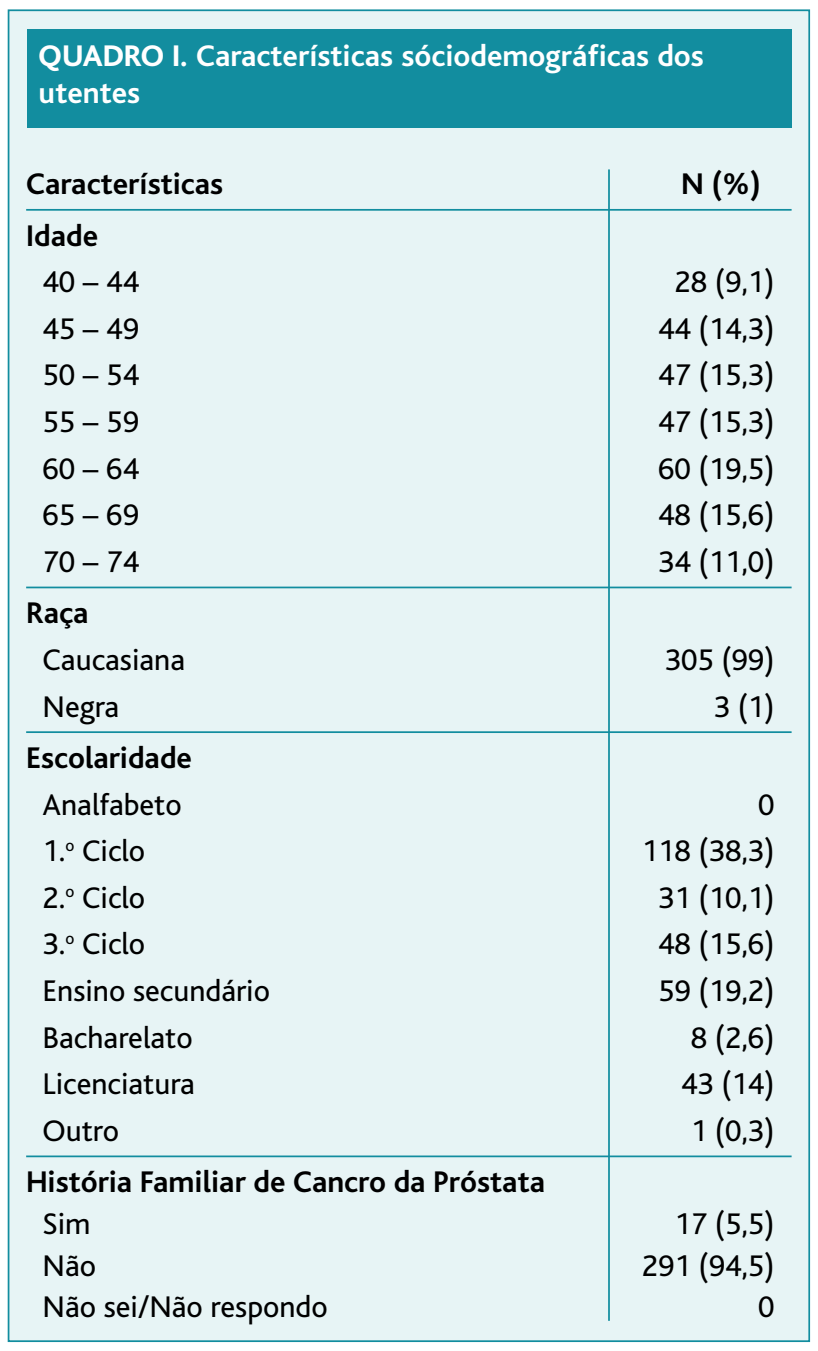

com os utentes $(p=0,818 ; p=0,199 ; p=0,147 ; p=0,183$, respetivamente).

Os utentes que tinham história familiar de cancro da próstata $(n=17)$ foram aqueles que mais responderam já terem ouvido falar e já terem realizado o teste PSA e exame do TR ( $p<0,001 ; p<0,001 ; p<0,001 ; p<0,001)$, assim como foram aqueles que mais afirmaram já terem discutido com o MF sobre teste PSA e suas vantagens e desvantagens $(p<0,001 ; p<0,001 ; p<0,001)$.

\section{DISCUSSÃO}

\section{Conhecimentos sobre os métodos de rastreio}

Os nossos resultados mostram que esta população de utentes tem um maior grau de conhecimento e já reali- 


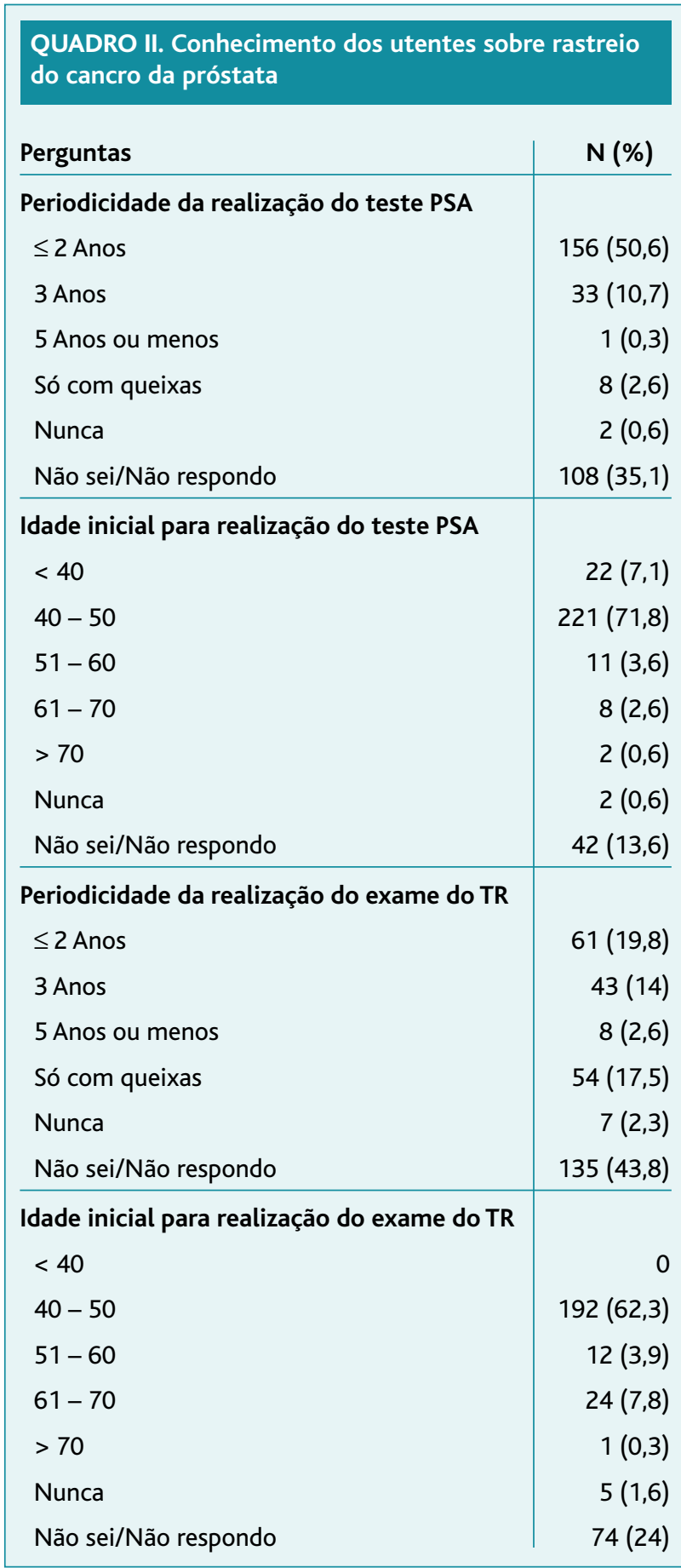

zou mais vezes o teste PSA do que o TR, apesar de a NOC da DGS, de 2011, ${ }^{6}$ recomendar o uso em simultâneo de ambos os métodos de rastreio. Esta situação poderá de- ver-se ao facto de ser mais simples a prescrição de uma análise ao sangue do que a realização de um exame desconfortável, tanto para o médico como para o utente.

Dados nacionais de $2007,{ }^{1}$ mostram que, numa amostra de 2.201 homens com mais de 35 anos, 38\% dos homens inquiridos já tinham ouvido falar do teste PSA, $21 \%$ já tinham realizado este exame e $1 / 4$ destes utentes já tinha sido submetido a um TR, pelo menos uma vez. Esta população é consideravelmente maior do que a do nosso estudo e envolve diferentes grupos etários - indivíduos mais jovens, que podem não ter ouvido falar nem realizado o teste PSA por não haver indicação para o fazer.

Em 2012, Smith et al ${ }^{14}$ aplicaram um questionário a homens canadianos com idades entre 41-80 anos (média de idades de 59 anos) em duas clínicas de cuidados de saúde primários e verificaram que $60 \%$ dos homens da sua amostra $(n=72)$ afirmaram já ter discutido com o seu MF sobre o teste PSA e cerca de $49 \%$ tinham realizado este exame nos últimos dois anos - dados mais próximos dos nossos.

Usando o National Health Interview Survey de 2000, dos Estados Unidos, Ross et $a l^{13}$ verificaram numa população de afro-americanos com mais de 45 anos $(n=736)$ que $63 \%$ já tinham ouvido falar do teste PSA e $48 \%$ já tinham realizado a análise, dados também semelhantes aos deste estudo.

Os utentes desta USF que ouviram falar do teste PSA e do exame TR eram mais velhos e tinham história familiar de cancro da próstata. Santos et al ${ }^{1}$ também mostraram que, com o aumento da idade, existiu um aumento da percentagem de homens que já tinham ouvido falar em teste PSA e Ross et al ${ }^{13}$ concluíram que, ter história familiar de cancro da próstata, estava relacionado com ter ouvido falar no teste PSA.

Estes resultados podem ser explicados por existir uma maior probabilidade de utentes com história familiar de cancro da próstata proporem mais vezes ao seu médico a realização deste rastreio ${ }^{16}$ ou os MF estarem mais preocupados em discutir e realizar o rastreio a utentes com idades mais elevadas ou com história familiar deste carcinoma. ${ }^{17}$

Portanto, verifica-se que muitos utentes desta USF do Grande Porto estão familiarizados com os exames preconizados para o rastreio do cancro da próstata, apesar de que os MF deveriam informar mais os utentes sobre o exame do TR e não só sobre o teste PSA. Este conhecimento apenas não é suficiente para o utente poder tomar uma decisão informada, mas é o primeiro passo. 


\section{Conhecimentos sobre o rastreio do cancro da próstata}

Verificou-se que cerca de metade dos utentes afirmaram que o teste PSA deveria ser realizado pelo menos de dois em dois anos e $71,8 \%$ concordam que deveria ser a partir dos 40 - 50 anos, o que vai de encontro às recomendações referentes à NOC, da DGS, de $2011 .{ }^{6}$ Relativamente ao exame do TR houve muitos utentes que ou não sabiam ou optaram por não responder às perguntas sobre periodicidade e idade inicial (43,8\% e $24 \%$, respetivamente); contudo, a maioria dos restantes respondeu que a periodicidade deveria ser pelo menos a cada dois anos ou então só quando o utente apresentasse sintomatologia (37,3\%) e a idade inicial deveria ser os $40-50$ anos (62,3\%). Estes resultados podem ser novamente explicados pela maior facilidade em prescrever o PSA do que realizar um TR, o que leva a um menor conhecimento por parte dos utentes sobre o TR para o rastreio do cancro da próstata.

No estudo de Livingston et al $^{15}$, de 2001, demonstrouse que $68 \%$ de uma população de homens com idade $\geq$ 49 anos, que foram contactados telefonicamente para preencher um questionário, acreditavam que o teste PSA devesse ser realizado pelo menos a cada dois anos, o que é semelhante ao nosso resultado.

\section{Discussão das vantagens e desvantagens do rastreio}

Mais de metade dos utentes declarou que o MF discutiu as vantagens de realizar este exame, ao passo que apenas $20,1 \%$ afirmaram o mesmo sobre as desvantagens do exame. Smith et al $^{14}$ demonstraram que a maioria dos homens acreditava que o teste PSA para rastreio do cancro da próstata não apresentava riscos, possivelmente por também não terem sido discutidas as desvantagens do método com o MF. No estudo de Chan et $a l^{18}$, de 2003, verificou-se que menos de metade dos homens (de uma população de utentes em Houston, 185 caucasianos e 86 afro-americanos com média de idades de 61,8 e 60,7 anos, respetivamente) declararam ter discutido com o seu médico sobre as vantagens/desvantagens do teste PSA; no entanto, não fizeram distinção entre vantagens e desvantagens e por essa razão não sabemos se os utentes responderiam de igual forma se estas duas variáveis estivessem separadas. Estes resultados sugerem que os MF podem estar a informar mais sobre as vantagens por acreditarem que o rastreio deve ser efetuado. ${ }^{19}$
A idade dos doentes não estava relacionada com esta partilha de informação; porém, foram os utentes com história familiar de cancro da próstata que afirmaram mais vezes ter discutido as vantagens e desvantagens do teste PSA com o seu MF.

Muito provavelmente, os utentes com história familiar de cancro da próstata questionam mais o MF acerca deste rastreio, o que leva a uma maior discussão das suas vantagens e desvantagens.

Concluiu-se que os MF deveriam informar mais os utentes sobre as desvantagens deste exame antes de o prescreverem para ajudar os utentes a tomar uma decisão informada.

Os investigadores optaram por selecionar uma amostra entre os 40 e os 75 anos, exclusive, visto ter-se verificado ser o intervalo recomendado pela DGS na NOC em vigor em $2011^{6}$ e por se ter verificado que a prevalência de cancro da próstata abaixo dos 40 anos é muito baixa ${ }^{11} \mathrm{e}$ nos homens com mais de 75 anos os benefícios deste rastreio serem de tal forma pequenos, ou mesmo inexistentes, que os malefícios superam os potenciais benefícios. ${ }^{17}$

Atualmente, a NOC da DGS ${ }^{20}$ foi atualizada e recomenda a deteção precoce ou oportunista aos homens que o solicitem, após serem devidamente informados sobre os riscos e benefícios do sobrediagnóstico e hipertratamento, através do PSA Total, com ou sem a palpação da próstata. Este último dado está relacionado com o facto de ter sido evidenciado que o TR não reduz a mortalidade quando usado em conjunto com o PSA. ${ }^{10}$

A NOC da DGS, na qual se baseou este trabalho, ${ }^{6}$ focava o estudo ERSPC (European Randomized Study of Screening for Prostate Cancer ${ }^{21}$ que demonstrou existir uma redução na mortalidade por cancro da próstata de aproximadamente uma morte por 1.000 homens rastreados dos 55 aos 69 anos; no entanto, além destes resultados terem sido principalmente influenciados pelos dados de dois países, Suécia e Holanda, no estudo PLCO (Prostate, Lung, Colorectal and Ovarian), ${ }^{19}$ não citado na NOC de 2011, verificou-se não existir diminuição da mortalidade específica ou geral com o rastreio através do PSA.

\section{Limitações}

Neste estudo existiram diversas limitações. Não se pode efetuar uma extrapolação dos resultados para a população portuguesa, uma vez que a amostra de utentes teve por base os utentes de uma só unidade de saúde do Grande 
Porto; outras USF podem ter resultados muito diferentes dos nossos. Este ponto pode ser facilmente contornado, envolvendo mais unidades de diversas áreas do país.

Poderá ter havido um viés de informação por não ter existido validação dos questionários aplicados. Apenas foi efetuado um teste-piloto para tentar minimizar esta questão. Além disso, devido ao facto dos questionários terem sido aplicados por entrevista telefónica conduzida pelos investigadores (médicos da USF em questão) poderão ter existido respostas diferentes. Este aspeto poderia ter sido contornado, enviando o questionário pelo correio para os utentes da amostra obtida ou poderia ter sido usada uma amostra de conveniência, sendo o questionário entregue pelos administrativos da USF e preenchido na sala de espera.

O questionário criado não espelhou totalmente o conhecimento dos utentes sobre as vantagens e desvantagens do rastreio do cancro da próstata, na medida em que só foi perguntado se os utentes tinham discutido estes aspetos com o MF. Sugere-se que num próximo trabalho se efetuem questões dirigidas para a avaliação deste conhecimento, visto ser necessário para o utente tomar uma decisão informada.

O aumento do tamanho amostral, de forma a tentar garantir medidas de capacidade de trabalho estatístico com objetivo significativo, poderá ter criado um viés de seleção, ou seja, aumentando o tamanho da amostra poderão ter sido incluídos mais utentes que não são representativos da população em questão.

O viés de autorrelato está relacionado com a vontade de responder o considerado mais correto pelo utente. $\mathrm{O}$ utente poderá ter respondido que já tinha ouvido falar do PSA ou que o MF tinha discutido as vantagens e desvantagens sobre esta análise por achar que a sociedade espera de si uma resposta afirmativa.

O preenchimento deste questionário poderá ter sido influenciado por um viés de memória, tendo em conta que os utentes podem não se ter lembrado de ter ouvido falar no PSA/TR ou de ter discutido este rastreio e as suas vantagens ou desvantagens com o seu MF ou com outro médico.

Apesar das limitações referidas, este estudo apresenta pontos fortes. Foi obtida uma amostra considerável de utentes, tendo existido poucos utentes que não quiseram participar. Considera-se o tema pertinente, visto ser um assunto que gera grande discórdia e é importante no con- texto da Medicina Geral e Familiar. É importante realizar a melhor abordagem relativamente ao cancro da próstata e de momento é recomendado que o utente esteja informado desta problemática para poder tomar uma decisão informada sobre este aspeto da sua saúde.

\section{CONCLUSÃO}

Os utentes desta USF do Grande Porto estão moderadamente informados sobre os métodos de rastreio do cancro da próstata, nomeadamente o teste PSA e o TR, à luz da NOC da DGS, de 2011. A maioria afirma conhecer as vantagens do teste PSA; contudo, poucos afirmam conhecer as desvantagens.

Futuramente, os autores sugerem que se realizem mais estudos nesta área com base nas normas atualizadas e, de preferência, com o envolvimento de mais USF, de forma a poder ser verificado se os MF continuam a prescrever indiferenciadamente o teste PSA para o rastreio do cancro da próstata a todos os seus utentes, sem estes estarem suficientemente informados sobre o assunto.

\section{AGRADECIMENTOS}

Gostaríamos de agradecer à Dra. Georgina Cruz e à Prof. Dra. Luciana Couto, médicas da USF Camélias e orientadoras de formação, por terem apoiado este projeto e contribuído para a sua revisão. Também gostaríamos de agradecer ao aluno de Licenciatura em Gestão Hoteleira, da Escola Superior de Estudos Industriais e de Gestão do Instituto Politécnico do Porto, Miguel Silva, pela contribuição neste trabalho.

\section{REFERÊNCIAS BIBLIOGRÁFICAS}

1. Santos A, Gonçalves N, Santos MJ, Rolo F, Macedo A. Avaliação de práticas e conhecimentos dos homens relativamente a doença prostática, em Portugal: estudo epidemiológico. Acta Urol. 2007;24(4):25-32. Portuguese

2. Nunes P, Pimentel FL, Pina F, Rolo F. Registo nacional de cancro da próstata, em Portugal - ReNaCap [National registry of prostate cancer, in Portugal - ReNaCaP]. Acta Urol. 2010;27(3):39-45. Portuguese

3. Programa Nacional para as Doenças Oncológicas. Portugal - Doenças oncológicas em números, 2014. Lisboa: Direção-Geral da Saúde; 2014.

4. American Cancer Society. Overview: prostate cancer prevention and early detection. What is prostate cancer? American Cancer Society; 2013 [cited 2013 Apr 20; updated 2012 Feb 27]. Available from: http://www.cancer.org/acs/groups/cid/documents/webcontent/003182-pdf.pdf

5. Hoffman RM, Couper MP, Zikmund-Fisher BJ, Levin CA, McNaughton-Collins $M$, Helitzer DL, et al. Prostate cancer screening decisions: results from the National Survey of Medical Decisions (DECISIONS study). Arch Intern Med. 2009;169(17):1611-8.

6. Direção-Geral da Saúde. Prescrição e determinação do antigénio específico da próstata - PSA: norma da DGS nº 060/2011. Lisboa: DGS; 2014.

7. Ilic D, Neuberger MM, Djulbegovic M, Dahm P. Screening for prostate 
cancer. Cochrane Database Syst Rev. 2013;1:CD004720.

8. Heidenreich A, Bastian PJ, Bellmunt J, Bolla M, Joniau S, Mason MD, et al. Guidelines on prostate cancer. Arnhem: European Association of Urology; 2011.

9. Carroll P, Albertsen PC, Greene K, Babaian RJ, Carter HB, Gann PH, et al. Prostate-specific antigen best practice statement: 2009 update. Linthicum: American Urological Association; 2009 [cited 2013 Apr 20]. Available from: http://www.auanet.org/content/guidelines-and-qualitycare/clinical-guidelines/main-reports/psa09.pdf.

10. Bell N, Gorber SC, Shane A, Joffres M, Singh H, Dickinson J, et al. Recommendations on screening for prostate cancer with the prostate-specific antigen test. CMAJ. 2014;186(16):1225-34.

11. Moyer VA, U. S. Preventive Services Task Force. Screening for prostate cancer: U. S. Preventive Services Task Force recommendation statement. Ann Intern Med. 2012;157(2):120-34.

12. Santos JA. Rastreio do cancro prostático: o actual paradigma da medicina centrada na pessoa [Prostate cancer screening in the light of person-centered medicine]. Rev Port Med Geral Fam. 2014;30(2):122-8. Portuguese

13. Ross LE, Uhler RJ, Williams KN. Awareness and use of the prostate-specific antigen test among African-American men. J Natl Med Assoc. 2005;97(7):963-71.

14. Smith SD, Birtwhistle R. Exploring patient perceptions of PSA screening for prostate cancer. Can Fam Physician. 2012;58(9):e502-7.

15. Livingston P, Cohen P, Frydenberg M, Borland R, Reading D, Clarke V, et al. Knowledge, attitudes and experience associated with testing for prostate cancer: a comparison between male doctors and men in the community. Intern Med J. 2002;32(5-6):215-23.

16. Taylor KL, DiPlacido J, Redd WH, Faccenda K, Greer L, Perlmutter A. Demographics, family histories and psychological characteristics of prostate carcinoma screening. Cancer. 1999;85(6):1305-12.
17. Curran V, Solberg S, Mathews M, Church J, Buehler S, Wells J, et al. Prostate cancer screening attitudes and continuing education needs of primary care physicians. J Cancer Educ. 2005;20(3):162-6.

18. Chan EC, Vernon SW, O'Donnell FT, Ahn C, Greisinger A, Aga DW. Informed consent for cancer screening with prostate-specific antigen: how well are men getting the message? Am J Public Health. 2003;93(5):779-85.

19. Hoffman RM, Papenfuss MR, Buller DB, Moon TE. Attitudes and practices of primary care physicians for prostate cancer screening. Am J Prev Med. 1996;12(4):277-81.

20. Schröder FH, Hugosson J, Roobol MJ, Tammela TL, Ciatto S, Nelen V, et al. Screening and prostate-cancer mortality in a randomized European study. N Engl J Med. 2009;360(13):1320-8.

21. Andriole GL, Crawford ED, Grubb RL III, Buys SS, Chia D, Church TR, et al. Mortality results from a randomized prostate cancer screening trial. $\mathrm{N}$ Engl J Med. 2009;360(13):1310-9.

\section{CONFLITO DE INTERESSES}

Os autores declaram não ter conflitos de interesses.

\section{COMISSÃO DE ÉTICA}

Estudo realizado após parecer favorável da Comissão de Ética da Saúde da ARS Norte.

\section{ENDEREÇO PARA CORRESPONDÊNCIA}

Marta Maria da Costa Magalhães

Rua da Palmeira, 120, 4430-163 Vila Nova de Gaia

E-mail: martacmagalhaes@gmail.com

Recebido em 09-09-2014

Aceite para publicação em 15-04-2015

\section{ABSTRACT \\ PATIENTS' KNOWLEDGE OF PROSTATE CANCER SCREENING IN A PRIMARY CARE CLINIC IN THE PORTO REGION}

Objective: To assess patients' knowledge of prostate cancer screening in a Family Health Unit in the North of Portugal (USF Camélias). Study Design: Cross sectional.

Setting: USF Camélias.

Population: Male patients between 40 and 75 years old in USF Camélias.

Methods: From a population of 3067 males, a stratified random sample of 500 individuals was selected. We assessed patients' knowledge of prostate cancer screening in a telephone survey.

Results: Of the 308 men who completed the survey, $77.9 \%$ had heard about prostate specific antigen (PSA) (47.7\% from their family doctor). Most stated that men should have a PSA test performed at least every two years starting at 40-50 years of age. Regarding digital rectal examination (DRE), $43.8 \%$ did not respond or claimed they did not know the recommendation for the examination. Conclusion: The patients surveyed had a moderate knowledge about prostate cancer screening. In order to better understand knowledge of prostate cancer screening in Portugal, more studies in a wider setting are required.

Keywords: Prostate-specific Antigen; Screening; Knowledge. 


\section{ANEXO I}

1. Data de nascimento:

2. Raça/Etnia
$\square$ Caucasiana
$\square$ Negra
$\square$ Asiática
$\square$ Outra (Qual?

3. Escolaridade
$\square$ Analfabeto
1..$^{\circ}$ Ciclo (até $4 .^{\circ}$ ano)
2..$^{\circ}$ Ciclo (até $9 .^{\circ}$ ano)
3. ${ }^{\circ}$ Ciclo (até $12 .^{\circ}$ ano)
Ensino secundário
Bacharelato
Licenciatura
$\square$ Outra

4. Alguma vez teve cancro da próstata?
$\square$ Sim
$\square$ Não
$\square$ Não sei/Não respondo

5. Tem algum familiar direto que já teve cancro da próstata?

$\square \operatorname{Sim}$

$\square$ Não

$\square$ Não sei/Não respondo

6. Já ouviu falar no teste PSA?
$\square \operatorname{Sim}$
$\square$ Não
$\square$ Não sei/Não respondo

A) Se respondeu sim, onde ouviu falar do teste PSA?
Médico de família
Outro

7. Já alguma vez realizou o teste PSA?
$\square$ Sim
$\square$ Não
$\square$ Não sei/Não respondo

8. O seu médico de família discutiu consigo as vantagens de realizar o teste PSA?
$\square$ Sim
$\square$ Não
$\square$ Não sei/Não respondo

9. O seu médico de família discutiu consigo as desvantagens de realizar o teste PSA?

$\square \operatorname{Sim}$

$\square$ Não

$\square$ Não sei/Não respondo
10. Na sua opinião, o teste PSA deve ser pedido de quanto em quanto tempo?
$\square$ Pelo menos de 2 em 2 anos
Cada 3 anos
$\square$ Cada 5 anos ou menos
$\square$ Só quando se tem queixas
$\square$ Nunca
$\square$ Não sei/Não respondo

11. Na sua opinião, o teste PSA deve ser pedido a partir de que idade?
$\square<40$
$40-50$
$51-60$
$61-70$
$>70$
Nunca
Não sei/Não respondo

12. Já ouviu falar no toque retal?
$\square$ Sim
$\square$ Não
$\square$ Não sei/Não respondo

A) Se respondeu sim, onde ouviu falar do toque retal?

$\square$ Médico de família

$\square$ Outro

13. Já alguma vez lhe fizeram um toque retal?
$\square \mathrm{Sim}$
$\square$ Não
$\square$ Não sei/Não respondo

14. Na sua opinião, o toque retal deve ser realizado de quanto em quanto tempo?
$\square$ Pelo menos de 2 em 2 anos
Cada 3 anos
Cada 5 anos ou menos
$\square$ Só quando se tem queixas
$\square$ Nunca
Não sei/Não respondo

15. Na sua opinião, o toque retal deve ser realizado a partir de que idade?
$\square<40$
40-50
$51-60$
$\square 61-70$
$\square>70$
$\square$ Nunca
$\square$ Não sei/Não respondo

Artigo escrito ao abrigo do novo acordo ortográfico. 